\title{
Modulation of Apoptosis and Differentiation by the Treatment of Sulfasalazine in Rabbit Articular Chondrocytes
}

\author{
Won Kil Lee and Jin Seok Kang \\ Department of Biomedical Laboratory Science, Namseoul University, Cheonan, Korea
}

(Received November 16, 2015; Revised December 18, 2015; Accepted January 29, 2016)

\begin{abstract}
This study was conducted to examine the cellular regulatory mechanisms of sulfasalazine (SSZ) in rabbit articular chondrocytes treated with sodium nitroprusside (SNP). Cell phenotype was determined, and the MTT assay, Western blot analysis and immunofluorescence staining of type II collagen was performed in control, SNP-treated and SNP plus SSZ $(50 \sim 200 \mu \mathrm{g} / \mathrm{mL})$ rabbit articular chondrocytes. Cellular proliferation was decreased significantly in the SNP-treated group compared with that in the control $(p<0.01)$. SSZ treatment clearly increased the SNP-reduced proliferation levels in a concentration-dependent manner $(p<0.01)$. SNP treatment induced significant dedifferentiation and inflammation compared with control chondrocytes $(p<0.01)$. Type II collagen expression levels increased in a concentration-dependent manner in response to SSZ treatment but were unaltered in SNP-treated chondrocytes $(p<0.05$ and $<0.01$, respectively). Cylooxygenase-2 (COX-2) expression increased in a concentration-dependent manner in response to SSZ treatment but was unaltered in SNP-treated chondrocytes $(p<0.05)$. Immunofluorescence staining showed that SSZ treatment increased type II collagen expression compared with that in SNP-treated chondrocytes. Furthermore, phosphorylated extracellular regulated kinase (pERK) expression levels were decreased significantly in the SNP-treated group compared with those in control chondrocytes $(p<0.01)$. Expression levels of pERK increased in a concentration-dependent manner by SSZ but were unaltered in SNP-treated chondrocytes. pp38 kinase expression levels increased in a concentrationdependent manner by SSZ but were unaltered in control chondrocytes $(p<0.01)$. In summary, SSZ significantly inhibited nitric oxide-induced cell death and dedifferentiation, and regulated extracellular regulated kinases 1 and 2 and p38 kinase in rabbit articular chondrocytes.
\end{abstract}

Key words: Chondrocyte, Sulfasalazine, Nitric oxide, Apoptosis, Differentiation

\section{INTRODUCTION}

Rheumatoid arthritis (RA) is one of the most common forms of autoimmune disease and is an inflammatory dis-

Correspondence to: Jin Seok Kang, Department of Biomedical Laboratory Science, Namseoul University, 91 Daehak-ro, Seonghwan-eup, Sebuk-gu, Cheonan 331-707, Korea

E-mail: kang@nsu.ac.kr

Abbreviations: COX-2, Cyclooxygenase-2; DAPI, 4', 6'-diamidine-2'phenylindole dihydrochloride; DMEM, Dulbecco's modified Eagle's medium; ELISA, Enzyme-linked immunosorbent assay; ERK-1/-2, Extracellular signal-regulated kinases-1/-2; FITC, Fluorescein isothiocyanate; GAPDH, Glyceraldehyde 3-phosphate dehydrogenase; MAP kinase, Mitogen-activated protein kinases; NO, Nitric oxide; OA, Osteoarthritis; PBS, Phosphate buffered saline; RA, Rheumatoid arthritis; SNP, Sodium nitroprusside; SSZ, Sulfasalazine.

This is an Open-Access article distributed under the terms of the Creative Commons Attribution Non-Commercial License (http:// creativecommons.org/licenses/by-nc/3.0) which permits unrestricted non-commercial use, distribution, and reproduction in any medium, provided the original work is properly cited. ease of the joint with an unknown cause. This disease can occur at any age (1-5). RA is distinguished by chronic inflammation of multiple joints with associated systemic symptoms, such as weakness. Inflammation induces joint pain, stiffness, and swelling, causing loss of joint function due to destruction of cartilage and bone, often leading to progressive disability (6-11). Patients with RA also have an increased risk of developing other systemic complications such as osteoporosis, anemia, and other disorders affecting the lungs and skin. The main characteristic of the disease is inflammation of the joint synovial tissues. The synovium is present as a thin, specialized tissue that is responsible for producing fluid $(1,12-15)$. The synovium becomes swollen in patients with RA and many inflammatory cells appear. Inflammation of the joints causes a release of enzymes from the inflammatory cells that are attracted to the synovial tissue (16-18). These enzymes destroy the synovial tissue and can continue into bone, damaging the joint so that it is unable to perform its basic function.

Arthritis is a chronic health problem. However, the molec- 
ular mechanism of cartilage degeneration is largely unknown $(5,19,20)$. The aim of this study was to understand the basic molecular mechanism of cartilage degeneration, which is important for therapy in patients with degenerative cartilage disease.

One of the main mechanisms by which cytokines elicit their effects on cartilage involves stimulation of nitric oxide (NO) production via stimulation by inducible NO synthase $(21,22)$. Although NO-induced cartilage destruction is caused by various factors, increased apoptotic cell death (23-25) and loss of the differentiated phenotype of articular chondrocytes $(26,27)$ appear to be important contributors. Our previous results showed that direct production of $\mathrm{NO}$ in primary cultured articular chondrocytes by the NO donor sodium nitroprusside (SNP) leads to apoptosis, dedifferentiation, and cyclooxygenase-2 (COX-2) expression via a complex protein kinase signaling cascade involving mitogenactivated protein kinase (MAPK) (28-30).

Sulfasalazine (SSZ) is an antiinflammatory agent widely used in humans to treat inflammatory bowel diseases such as ulcerative colitis and Crohn's disease $(31,32)$. SSZ is also used to treat patients with RA $(33,34)$. SSZ is metabolized to sulfapyridine and 5'-aminosalicylic acid by bacteria in the lower intestinal tract $(35,36)$. Of the two major metabolites, sulfapyridine is relatively well-absorbed from the intestine and further metabolized by $\mathrm{N}$-acetylation, whereas 5 '-aminosalicylic acid is not absorbed as well $(35,36)$. In humans, the absolute bioavailability of orally administered SSZ is $<15 \%$ (37-39). This lower bioavailability has been largely attributed to limited solubility and poor permeability (40).

The purpose of this study was to examine the RA cellular regulatory mechanisms via SSZ in rabbit articular chondrocytes. Other studies have provided cell signaling information by identifying the cellular control mechanisms. Therefore, we identified the regulatory mechanisms of differentiation and inflammation by SSZ in rabbit articular chondrocytes.

\section{MATERIALS AND METHODS}

Primary chondrocyte culture. Rabbit articular chondrocytes were isolated from cartilage slices of 2-week-old New Zealand white rabbits by enzymatic digestion, as described previously (41). The cartilage slices were dissociated enzymatically for $6 \mathrm{hr}$ in $0.2 \%$ collagenase type II (381 U/mg solid; Sigma, St. Louis, MO, USA) in Dulbecco's Modified Eagle's Medium (DMEM) (Gibco-BRL, Gaithersburg, MD, USA). Individual cells were suspended in DMEM supplemented with $10 \%(\mathrm{v} / \mathrm{v})$ fetal bovine calf serum, $50 \mathrm{~g} / \mathrm{mL}$ streptomycin, and 50 units $/ \mathrm{mL}$ penicillin. Cells were plated onto culture dishes at a density of $5 \times 10^{4}$ / $\mathrm{cm}^{2}$. The medium was changed every 2 days after seeding, and cells reached confluence in approximately 5 days. This study was approved by the animal ethics committee of Kongju National University according to the Animal Protection Act.
Cell proliferation assay. The MTT assay was used to quantify the proliferation of cells treated with SSZ and SNP. Cells were seeded onto 96-well plates at a density of $2 \times 10^{4} /$ well for $24 \mathrm{hr}$ and then treated with SSZ or SNP plus SSZ. A $10 \mu \mathrm{L}$ aliquot of MTT reagent 1 was added to each well. The plate was incubated for $4 \mathrm{hr}$ at $37^{\circ} \mathrm{C}$ until purple formazan crystals developed. Then, $100 \mu \mathrm{L}$ of MTT reagent 2 was added to each well. After an overnight incubation, the absorbance was read at $600 \mathrm{~nm}$ with a spectrophotometer in four wells per treatment group.

Western blot analysis. Whole cell lysates were prepared by extracting proteins using a buffer containing $50 \mathrm{mM}$ Tris- $\mathrm{HCl}, \mathrm{pH} 7.4,150 \mathrm{mM} \mathrm{NaCl}, 1 \%$ Nonidet P-40, and $0.1 \%$ sodium dodecyl sulfate (SDS), supplemented with protease inhibitors $(10 \mathrm{~g} / \mathrm{mL}$ leupeptin, $10 \mathrm{~g} / \mathrm{mL}$ pepstatin A, $10 \mathrm{~g} / \mathrm{mL}$ aprotinin, $1 \mathrm{mM}$ 4-[2-aminoethyl] benzenesulfonyl fluoride, and $1 \mathrm{mM} \mathrm{NaF}$ and $1 \mathrm{mM} \mathrm{Na}_{3} \mathrm{VO}_{4}$ as phosphatase inhibitors). The proteins were size-fractionated by SDS-polyacrylamide gel electrophoresis (PAGE) and transferred to a nitrocellulose membrane. The membrane was blocked with $3 \%$ non-fat dry milk in Tris-buffered saline. The following antibodies were used: COX-2 (Cayman Chemical, Ann Arbor, MI, USA) and type II collagen (Santa Cruz Biotechnology Inc., Santa Cruz, CA, USA). Western blots were developed using a peroxidase-conjugated secondary antibody and a chemiluminescence system.

Immunofluorescence staining. Expression and distribution of type II collagen in rabbit articular chondrocytes were determined by indirect immunofluorescence microscopy, as described previously (42). Briefly, chondrocytes were fixed with $3.5 \%$ paraformaldehyde in phosphate-buffered saline (PBS) for $10 \mathrm{~min}$ at room temperature. The cells were permeated and blocked with $0.1 \%$ Triton X-100 and $5 \%$ fetal calf serum in PBS for $30 \mathrm{~min}$. The fixed cells were washed and incubated for $1 \mathrm{hr}$ with an antibody $(10 \mathrm{~g} / \mathrm{mL})$ against type II collagen. The cells were washed, incubated with rhodamine- or fluorescein-conjugated secondary antibodies for $30 \mathrm{~min}$, and observed under a fluorescence microscope.

Statistical analysis. Statistical analyses were performed using GraphPad Prism 6 (GraphPad Software, La Jolla, CA, USA). All data were analyzed using Student's $t$-test and are expressed as the mean \pm standard deviation. $P$-values $<0.05$ were considered significant.

\section{RESULTS}

NO induces apoptosis and dedifferentiation of rabbit articular chondrocytes. NO mediates the regulation and survival of the chondrocyte phenotype by inducing apoptosis and differentiation. To assess the anti-apoptotic effect of 
(A)

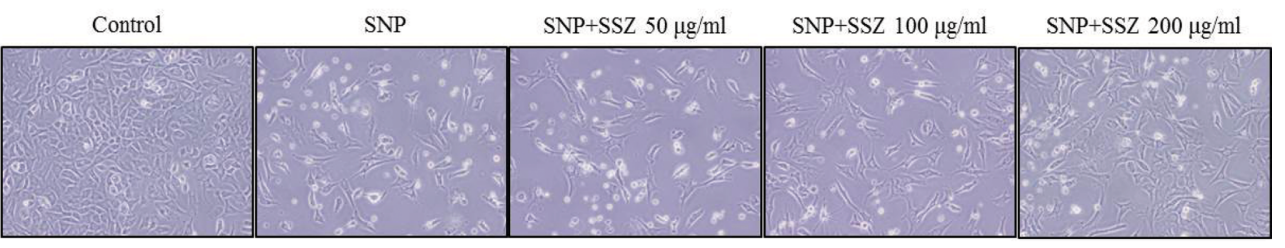

(B)

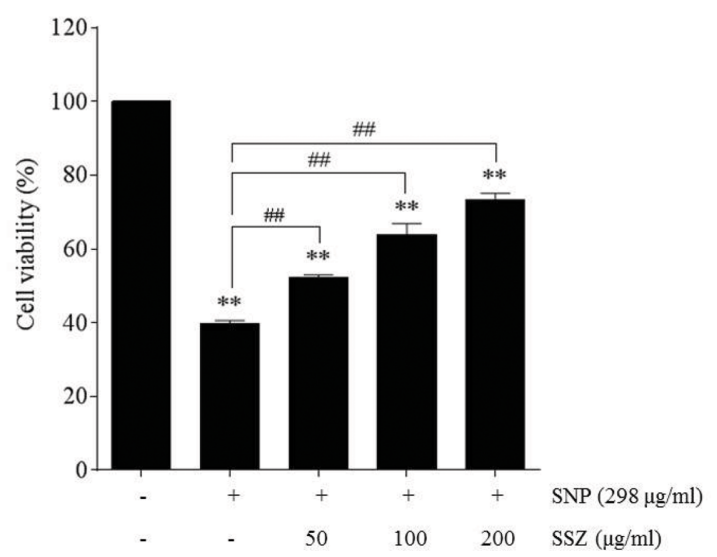

Fig. 1. Effects of sulfasalazine (SSZ) on the morphological change and proliferation in chondrocyte cells. Rabbit articular chondrocytes untreated (control) or treated with $298 \mu \mathrm{g} / \mathrm{mL} \mathrm{SNP}$ and $50 \sim 200 \mu \mathrm{g} / \mathrm{mL}$ of SSZ plus $298 \mu \mathrm{g} / \mathrm{mL}$ of SNP at 24 hr. (A) The apoptotic cells death was determined by phase-contrast microscope (magnification, 200X). (B) Primary chondrocytes apoptosis were determined by MTT assay. " Significantly different compared from control; "\#Significantly different compared from SNP treatment $(p<0.01)$; Values were presented as the mean \pm SD.

(A)

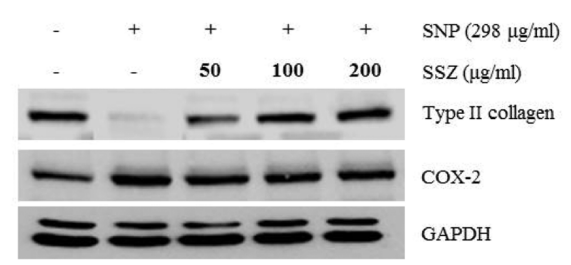

(B)

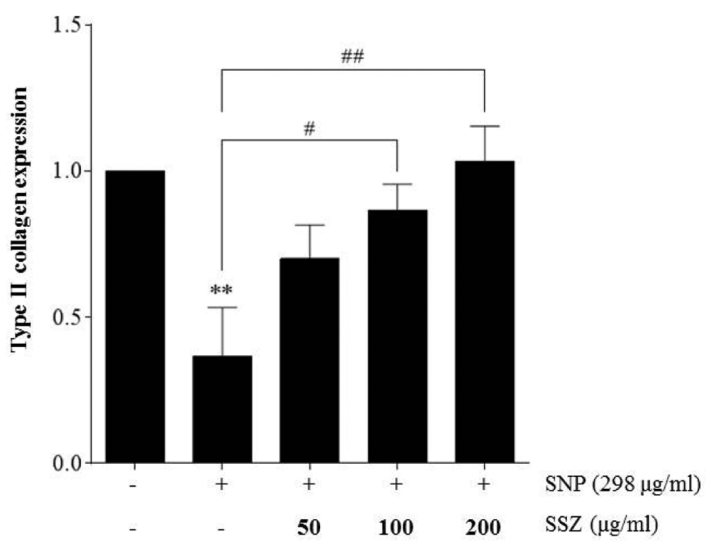

(C)

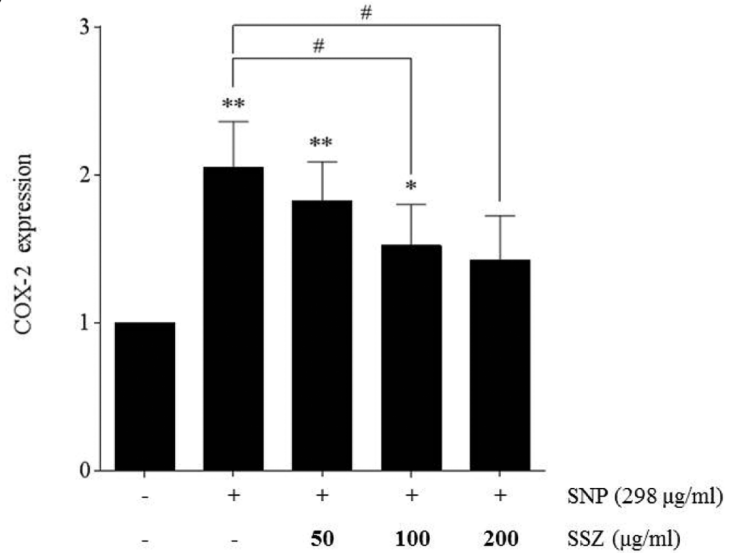

Fig. 2. Effects of sulfasalazine (SSZ) on SNP-induced dedifferentiation and inflammation in chondrocyte cells. (A) Rabbit articular chondrocytes treated $298 \mu \mathrm{g} / \mathrm{mL}$ of SNP and $50 \sim 200 \mu \mathrm{g} / \mathrm{mL}$ of SSZ plus SNP at $24 \mathrm{hr}$ and subjects to western blot analysis with antibodies type II collagen, COX-2 and glyceraldehyde 3-phosphate dehydrogenase (GAPDH). (B, C) It was determined that the protein levels of type II collagen and COX-2 were subsequently quantified by densitometry analysis. Expression of GAPDH was used as loading control. The data represented a typical experiment, whereby similar results obtained from three. ", Significantly different compared from con-

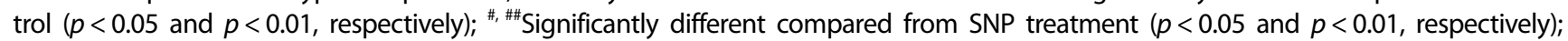
Values were presented as the mean \pm SD. 
SSZ in NO-induced apoptotic cells, various doses (50 200 $\mu \mathrm{g} / \mathrm{mL}$ ) of SSZ and $298 \mu \mathrm{g} / \mathrm{mL}$ SNP were used. Cell morphology, observed by phase-contrast microscopy, showed that NO-induced apoptosis was inhibited by SSZ (Fig. 1A). To investigate the role of SSZ in chondrocyte proliferation, cells were treated with SSZ and proliferation measured using the MTT assay. The level of cell proliferation decreased significantly in response to SNP treatment as compared with that in the control $(p<0.01)$. And SSZ treatment significantly increased SNP-reduced proliferation levels in a concentration-dependent manner $(p<0.01)$ (Fig. 1B).
Sulfasalazine causes differentiation in rabbit articular chondrocytes. Different SSZ concentrations regulated type II collagen and COX-2 expression, as determined by Western blot analysis of rabbit articular chondrocytes (Fig. 2A). Dedifferentiation and inflammation were significantly induced by SNP treatment compared with control chondrocytes $(p<0.01)$. And the expression levels of type II collagen increased in a concentration-dependent manner in response to SSZ treatment but were unaltered in SNPtreated chondrocytes $(p<0.05$ and $<0.01$, respectively) (Fig. 2B). COX-2 expression levels increased in a concen-

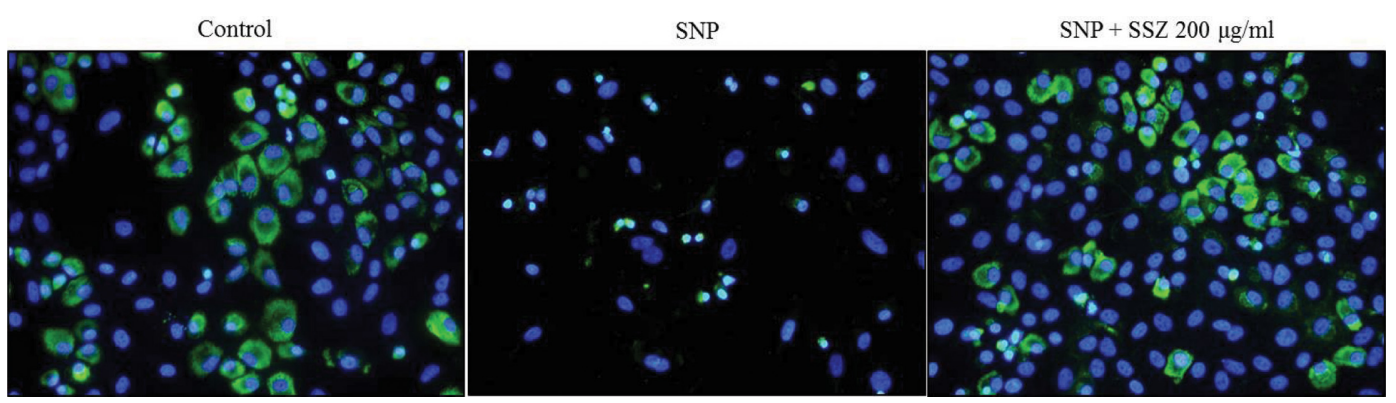

Fig. 3. Expression of type II collagen in chondrocyte by immunofluorescence staining. Rabbit articular chondrocytes untreated (control) or treated $298 \mu \mathrm{g} / \mathrm{mL}$ of SNP and $200 \mu \mathrm{g} / \mathrm{mL}$ of sulfasalazine (SSZ) plus SNP at $24 \mathrm{hr}$. Expression of type II collagen (green) and DAPI (blue) identify by immunofluorescence microscopy (200x).

(A)

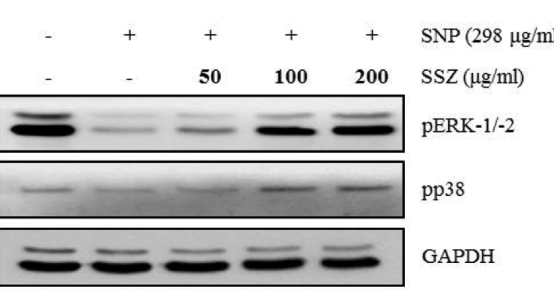

(B)

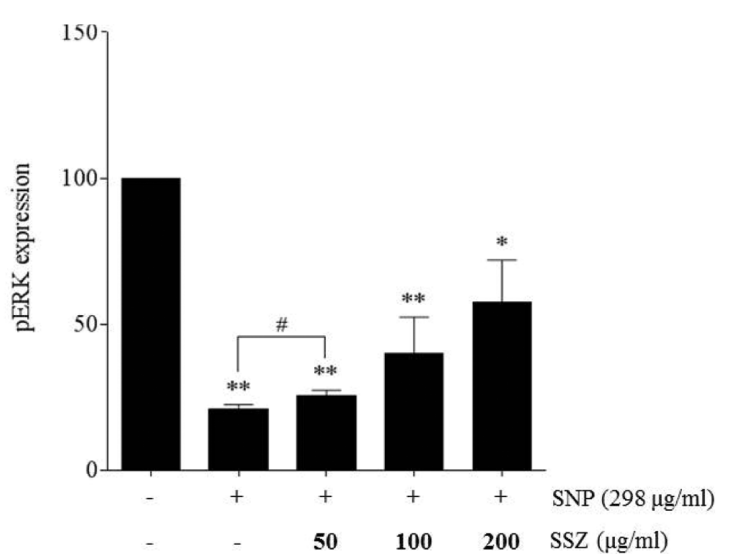

(C)

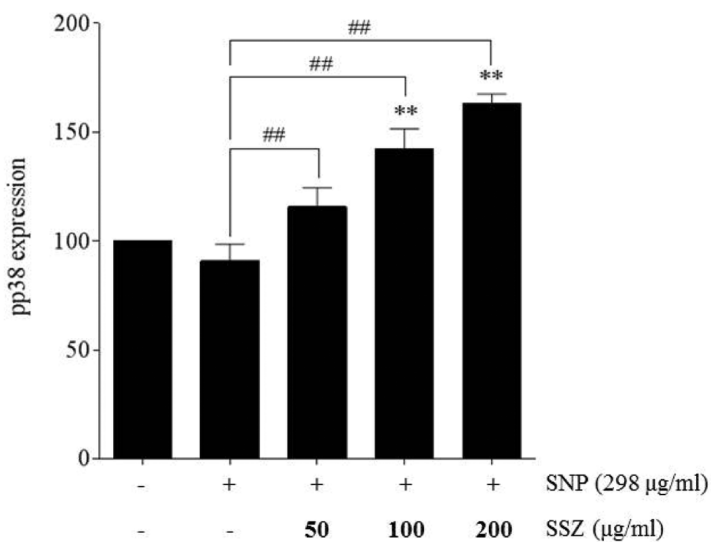

Fig. 4. Expression of pERK and pp38 kinase protein in chondrocyte cell by western blot analyses. (A) Rabbit articular chondrocytes treated $298 \mu \mathrm{g} / \mathrm{mL}$ of SNP and $50 \sim 200 \mu \mathrm{g} / \mathrm{mL}$ of sulfasalazine (SSZ) plus SNP at $24 \mathrm{hr}$ and subjects to western blot analysis with antibodies pERK, pp38 kinase and glyceraldehyde 3-phosphate dehydrogenase (GAPDH). (B, C) It was determined that the protein levels of pERK and pp38 kinase were subsequently quantified by densitometry analysis. Expression of GAPDH was used as loading control. The data represented a typical experiment, whereby similar results obtained from three. ${ }^{*, * * *}$ Significantly different compared from con-

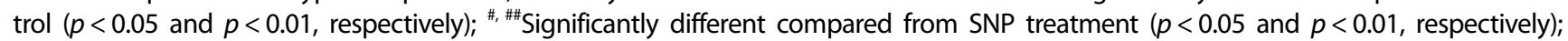
Values were presented as the mean \pm SD. 
tration-dependent manner in response to SSZ but were unaltered in SNP-treated chondrocytes $(p<0.05)$ (Fig. 2C). Immunofluorescence staining showed that SSZ increased type II collagen expression compared with SNP-treated chondrocytes (Fig. 3). Taken together, these results indicate that the SSZ-induced increase in type II collagen and decrease in COX-2 expression were sufficient to induce differentiation of articular chondrocytes.

\section{Sulfasalazine stimulates extracellular regulated kinases} 1 and 2 (ERK-1/-2) and p38 kinase in chondrocytes. pERK and pp38 kinase expression levels changed in response to $\mathrm{SSZ}$, as determined by Western blot analysis of rabbit articular chondrocytes (Fig. 4A). Expression levels of pERK decreased significantly by SNP compared with control chondrocytes $(p<0.01)$. And pERK expression levels increased in a concentration-dependent manner in response to SSZ but were unaltered in SNP-treated chondrocytes (Fig. 4B). Furthermore, pp38 kinase expression levels increased in a concentration-dependent manner in response to SSZ treatment but were unaltered in control chondrocytes $(p<$ 0.01) (Fig. 4C).

\section{DISCUSSION}

Articular cartilage is a major component of the joint, and its mechanical properties depend on the integrity of the extracellular matrix, which is composed mainly of proteoglycans and collagens (43). Differentiated chondrocytes lose their phenotype and transform into fibroblast-like cells upon exposure to soluble factors such as interleukin-1 (44), and NO (29), or during serial subculture in vitro (45). Such destruction of homeostasis is believed to be involved in the pathophysiology of arthritis, RA, and osteoarthritis (OA) $(46,47)$. Several inflammatory mediators, including NO, have been implicated in the disease processes of RA and OA. NO is produced by cytokine-stimulated chondrocytes in arthritis-affected cartilage via induction of COX-2 expression (48).

In this study, we demonstrated that SSZ caused a differentiated chondrocyte phenotype, as demonstrated by type II collagen expression in rabbit articular chondrocytes after $24 \mathrm{hr}$. Type II collagen is a well-known chondrocyte differentiation marker. SSZ treatment increased type II collagen expression in rabbit articular chondrocytes. These results suggest that SSZ induces differentiation in rabbit articular chondrocytes.

NO mediates the regulation and survival of the chondrocyte phenotype by inducing dedifferentiation, apoptosis, and inflammation. Apoptosis of chondrocytes is caused by direct production of NO, and SNP is regulated by the opposite functions of the two MAPK subtypes ERK-1/-2 and p38 kinase in association with apoptosis status and increased differentiation (28-30). SNP treatment activated both ERK-
1/-2 and p38 kinase in chondrocytes. Activated ERK-1/2 acts as an inhibitory signal for NO-induced apoptosis, whereas p38 kinase functions as a signal to maintain the differentiated status and as a signal to induce apoptosis in chondrocytes. In addition, a previous study showed that NO production in rabbit articular chondrocytes inhibited cell survival signaling (49).

In summary, SSZ treatment significantly inhibited NOinduced cell death, dedifferentiation, and inflammation, and regulated ERK-1/2 and p38 kinase in rabbit articular chondrocytes.

\section{ACKNOWLEDGEMENTS}

We would like to thank Ms. Joo Hye Sim (Namseoul University) for her technical assistance. Funding for this paper was provided by Namseoul University.

\section{CONFLICT OF INTEREST}

Authors declare that there are no conflicts of interest.

\section{REFERENCES}

1. Hadjigogos, K. (2003) The role of free radicals in the pathogenesis of rheumatoid arthritis. Panminerva Med., 45, 7-13.

2. Harris, E.D., Jr., Faulkner, C.S., 2nd and Brown, F.E. (1975) Collagenolytic systems in rheumatoid arthritis. Clin. Orthop. Relat. Res., (110), 303-316.

3. Dai, S.M., Shan, Z.Z., Xu, H. and Nishioka, K. (2007) Cellular targets of interleukin-18 in rheumatoid arthritis. Ann. Rheum. Dis., 66, 1411-1418.

4. Otero, M. and Goldring, M.B. (2007) Cells of the synovium in rheumatoid arthritis. Arthritis Res. Ther, 9, 220.

5. Scott, D.L., Wolfe, F. and Huizinga, T.W. (2010) Rheumatoid arthritis. Lancet, 376, 1094-1108.

6. Abramson, S.B. and Amin, A. (2002) Blocking the effects of IL-1 in rheumatoid arthritis protects bone and cartilage. Rheumatology (Oxford), 41, 972-980.

7. Carrillo Gutiérrez, O.Y., Pérez Sánchez, A.G., Medina Serriteño, N. and Rodríguez Orozco, A.R. (2007) Side effects of COX-2 selective inhibitors. Critic related with its administration in patients with rheumatoid arthritis and osteoarthritis. Rev. Alerg. Mex., 54, 116-122.

8. Chen, Y.F., Jobanputra, P., Barton, P., Bryan, S., Fry-Smith, A., Harris, G. and Taylor, R.S. (2008) Cyclooxygenase-2 selective non-steroidal anti-inflammatory drugs (etodolac, meloxicam, celecoxib, rofecoxib, etoricoxib, valdecoxib and lumiracoxib) for osteoarthritis and rheumatoid arthritis: a systematic review and economic evaluation. Health Technol. Assess., 12, 1-278.

9. Shiozawa, S. and Tokuhisa, T. (1992) Contribution of synovial mesenchymal cells to the pathogenesis of rheumatoid arthritis. Semin. Arthritis Rheum., 21, 267-273.

10. Tutuncu, Z. and Kavanaugh, A. (2007) Rheumatic disease in the elderly: rheumatoid arthritis. Rheum. Dis. Clin. North Am., 33, 57-70. 
11. Vergunst, C.E., van de Sande, M.G., Lebre, M.C. and Tak, P.P. (2005) The role of chemokines in rheumatoid arthritis and osteoarthritis. Scand. J. Rheumatol., 34, 415-425.

12. Combe, B. (1998) Inflammation and joint destruction during rheumatoid polyarthritis: what relation? Presse Med., 27, 481483.

13. Häuselmann, H.J. (1997) Mechanisms of cartilage destruction and novel nonsurgical therapeutic strategies to retard cartilage injury in rheumatoid arthritis. Curr. Opin. Rheumatol., 9, 241250.

14. Meyer, O, (2000) Role of anti-TNF therapy in rheumatoid arthritis. Presse Med., 29, 463-468.

15. Reines, B.P. (2004) Is rheumatoid arthritis premature osteoarthritis with fetal-like healing? Autoimmun. Rev., 3, 305-311.

16. Kastrinaki, M.C. and Papadaki, H.A. (2009) Mesenchymal stromal cells in rheumatoid arthritis: biological properties and clinical applications. Curr. Stem Cell Res. Ther., 4, 61-69.

17. Lombardi, A., Pignone, A., Perfetto, F., Tarquini, R., Partsch, G. and Matucci-Cerinic, M. (1993) The enzymatic mechanisms involved in the pathogenesis of rheumatoid arthritis and arthrosis. The role of metalloproteases and serine proteases in the breakdown of articular cartilage. Recenti Prog. Med., 84, 634-641.

18. Shiozawa, S. and Shiozawa, K. (1988) A review of the histopathological evidence on the pathogenesis of cartilage destruction in rheumatoid arthritis. Scand. J. Rheumatol. Suppl., 74, 65-72.

19. Bouffi, C., Djouad, F., Mathieu, M., Noël, D. and Jorgensen, C. (2009) Multipotent mesenchymal stromal cells and rheumatoid arthritis: risk or benefit? Rheumatology (Oxford), 48, 1185-1189.

20. Magliano, M. (2008) Obesity and arthritis. Menopause Int., 14, 149-154.

21. Amin, A.R. and Abramson, S.B. (1998) The role of nitric oxide in articular cartilage breakdown in osteoarthritis. Curr. Opin. Rheumatol., 10, 263-268.

22. Martel-Pelletier, J., Alaaeddine, N. and Pelletier. J.P. (1999) Cytokines and their role in the pathophysiology of osteoarthritis. Front. Biosci., 4, D694-D703.

23. Blanco, F.J., Guitian, R., Vázquez-Martul, E., de Toro, F.J. and Galdo, F. (1998) Osteoarthritis chondrocytes die by apoptosis. A possible pathway for osteoarthritis pathology. Arthritis Rheum., 41, 284-289.

24. Hashimoto, S., Ochs, R.L., Komiya, S. and Lotz, M. (1998) Linkage of chondrocyte apoptosis and cartilage degradation in human osteoarthritis. Arthritis Rheum., 41, 1632-1638.

25. Yatsugi, N., Tsukazaki, T., Osaki, M., Koji, T., Yamashita, S. and Shindo, H. (2000) Apoptosis of articular chondrocytes in rheumatoid arthritis and osteoarthritis: correlation of apoptosis with degree of cartilage destruction and expression of apoptosis-related proteins of p53 and c-myc. J. Orthop. Sci., $\mathbf{5}, 150-156$

26. Cao, M., Westerhausen-Larson, A., Niyibizi, C., Kavalkovich, K., Georgescu, H.I., Rizzo, C.F., Hebda, P.A., StefanovicRacic, M. and Evans, C.H. (1997) Nitric oxide inhibits the synthesis of type-II collagen without altering Col2A1 mRNA abundance: prolyl hydroxylase as a possible target. Biochem. $J .$, 324, 305-310.

27. Taskiran, D., Stefanovic-Racic, M., Georgescu, H. and Evans,
C. (1994) Nitric oxide mediates suppression of cartilage proteoglycan synthesis by interleukin-1. Biochem. Biophys. Res. Commun., 200, 142-148.

28. Kim, S.J., Hwang, S.G., Shin, D.Y., Kang, S.S. and Chun, J.S. (2002) p38 kinase regulates nitric oxide-induced apoptosis of articular chondrocytes by accumulating p53 via NFKB-dependent transcription and stabilization by serine 15 phosphorylation. J. Biol. Chem., 277, 33501-33508.

29. Kim, S.J., Ju, J.W., Oh, C.D., Yoon, Y.M., Song, W.K., Kim, J.H., Yoo, Y.J., Bang, O.S., Kang, S.S. and Chun, J.S. (2002) ERK-1/2 and p38 kinase oppositely regulate nitric oxideinduced apoptosis of chondrocytes in association with p53, caspase-3, and differentiation status. J. Biol. Chem., 277, 1332-1339.

30. Kim, S.J., Kim, H.G., Oh, C.D., Hwang, S.G., Song, W.K., Yoo, Y.J., Kang, S.S. and Chun, J.S. (2002) p38 kinase-dependent and -independent Inhibition of protein kinase $C \zeta$ and $-\alpha$ regulates nitric oxide-induced apoptosis and dedifferentiation of articular chondrocytes. J. Biol. Chem., 277, 30375-30381.

31. Klotz, U. (1985) Clinical efficacy of oral 5-aminosalicylic acid in the treatment of inflammatory bowel disease. Am. J. Gastroenterol., 80, 660.

32. Peppercorn, M.A. (1984) Sulfasalazine. Pharmacology, clinical use, toxicity, and related new drug development. Ann. Intern. Med., 101, 377-386.

33. Astbury, C., Taggart, A.J., Juby, L., Zebouni, L. and Bird, H.A. (1990) Comparison of the single dose pharmacokinetics of sulphasalazine in rheumatoid arthritis and inflammatory bowel disease. Ann. Rheum. Dis., 49, 587-590.

34. Plosker, G.L. and Croom, K.F. (2005) Sulfasalazine: a review of its use in the management of rheumatoid arthritis. Drugs, 65, 1825-1849.

35. Azadkhan, A.K., Truelove, S.C. and Aronson, J.K. (1982) The disposition and metabolism of sulphasalazine (salicylazosulphapyridine) in man. Br. J. Clin. Pharmacol., 13, 523-528.

36. Klotz, U. and Schwab, M. (2005) Topical delivery of therapeutic agents in the treatment of inflammatory bowel disease. Adv. Drug Deliv. Rev., 57, 267-279.

37. Friedman, G. (1986) Sulfasalazine and new analogues. Am. J. Gastroenterol., 81, 141-144.

38. Klotz, U. (1985) Clinical pharmacokinetics of sulphasalazine, its metabolites and other prodrugs of 5-aminosalicylic acid. Clin. Pharmacokinet., 10, 285-302.

39. van Hees, P.A., Bakker, J.H. and van Tongeren, J.H. (1980) Effect of sulphapyridine, 5-aminosalicylic acid, and placebo in patients with idiopathic proctitis: a study to determine the active therapeutic moiety of sulphasalazine. Gut., 21, 632-635.

40. Yazdanian, M., Glynn, S.L., Wright, J.L. and Hawi, A. (1998) Correlating partitioning and Caco-2 cell permeability of structurally diverse small molecular weight compounds. Pharm. Res., 15, 1490-1494.

41. Yoon, Y.M., Kim, S.J., Oh, C.D., Ju, J.W., Song, W.K., Yoo, Y.J., Huh, T.L. and Chun, J.S. (2002) Maintenance of differentiated phenotype of articular chondrocytes by protein kinase $\mathrm{C}$ and extracellular signal-regulated protein kinase. J. Biol. Chem., 277, 8412-8420.

42. Ryu, J.H., Kim, S.J., Kim, S.H., Oh, C.D., Hwang, S.G., Chun, C.H., Oh, S.H., Seong, J.K., Huh, T.L. and Chun, J.S. (2002) Regulation of the chondrocyte phenotype by $\beta$-cat- 
enin. Development, 129, 5541-5550.

43. Poole, A.R. (2003) Cartilage in health and disease in Arthritis and Allied Conditions (McCarthy, D.J. and Koopman, W.J. Ed.) Lea and Febiger, Philadelphia, pp. 279-333.

44. Goldring, M.B., Birkhead, J., Sandell, L.J., Kimura, T. and Krane, S.M. (1988) Interleukin 1 suppresses expression of cartilage-specific types II and IX collagens and increases types I and III collagens in human chondrocytes. J. Clin. Invest., 82, 2026-2037.

45. Benya, P.D., Padilla, S.R. and Nimni, M.E. (1978) Independent regulation of collagen types by chondrocytes during the loss of differentiated function in culture. Cell, 15, 1313-1321.

46. Gay, S., Gay, R.E. and Koopman, W.J. (1993) Molecular and cellular mechanisms of joint destruction in rheumatoid arthritis: two cellular mechanisms explain joint destruction? Ann.
Rheum. Dis., 52, S39-S47.

47. Sandell, L.J. and Aigner, T. (2001) Articular cartilage and changes in arthritis. An introduction: cell biology of osteoarthritis. Arthritis Res., 3, 107-113.

48. Myers, L.K., Kang, A.H., Postlethwaite, A.E., Rosloniec, E.F., Morham, S.G., Shlopov, B.V., Goorha, S. and Ballou, L.R. (2000) The genetic ablation of cyclooxygenase 2 prevents the development of autoimmune arthritis. Arthritis Rheum., 43, 2687-2693.

49. Oh, C.D., Chang, S.H., Yoon, Y.M., Lee, S.J., Lee, Y.S., Kang, S.S. and Chun, J.S. (2000) Opposing role of mitogenactivated protein kinase subtypes, erk-1/2 and p38, in the regulation of chondrogenesis of mesenchymes. J. Biol. Chem., 275, 5613-5619. 